\title{
Assessment of Mutations of Ha- and Ki-ras Oncogenes and the p53 Suppressor Gene in Seven Malignant Mesothelioma Patients Exposed to Asbestos
}

\section{-PCR-SSCP and Sequencing Analyses of Paraffin-Embedded Primary Tumors-}

\author{
Fumihiko KITAMURA ${ }^{1}$, Shunichi ARAKI ${ }^{1 *}$, Takeshi TANIGAWA ${ }^{1}$, \\ Hirotaro MIURA ${ }^{2}$, Hisamasa AKABANE ${ }^{3}$ and Ryu IWASAKI ${ }^{4}$ \\ ${ }^{1}$ Department of Public Health, Faculty of Medicine, University of Tokyo, 7-3-1, Hongo, Bunkyo-ku, Tokyo \\ 113, Japan \\ ${ }^{2}$ Department of Internal Medicine, Yokosuka Kyosai Hospital, 1-16, Yonegahama-dori, Yokosuka-City, Kanagawa \\ 238, Japan \\ ${ }^{3}$ Pathological Anatomy Service, Yokosuka Kyosai Hospital, 1-16, Yonegahama-dori, Yokosuka-City, Kanagawa \\ 238, Japan \\ ${ }^{4}$ Department of Gene Analysis, Mistubishi Kagaku Bio-Clinical-Laboratories, Inc., 3-30-1, Shimura, Itabashi-ku, \\ Tokyo 174, Japan
}

Received June 26, 1997 and accepted November 15, 1997

\begin{abstract}
To examine whether malignant mesothelioma due to asbestos has genetic alterations in the Ha- and Ki-ras oncogenes or in the p53 suppressor gene, we analyzed the point mutations of these genes in paraffin-embedded autopsy samples of the primary tumors of malignant mesothelioma in seven asbestos patients who died from malignant mesothelioma. The genetic analysis was conducted by the polymerase chain reaction-single strand comformation polymorphysms (PCR-SSCP) method in all patients, and through the sequencing of deoxyribonucleic acid (DNA) bases in one patient. No genetic alterations were found in exons 1 or 2 of $\mathrm{Ha}$ - and Ki-ras oncogenes, or in exons 5 to 9 of the p53 gene, in any of the patients. Further studies on a larger number of patients are required to reach a definite conclusion concerning the genetic effects of asbestos on malignant mesothelioma.
\end{abstract}

Key words: Asbestos, Malignant mesothelioma, Paraffin-embedded tissue, ras oncogene, p53 suppressor gene, PCR-SSCP analysis, Sequencing analysis

\section{Introduction}

There is evidence to suggest that the point mutation of oncogenes and suppressor genes is associated with occupational or environmental carcinogens ${ }^{1}$. For example, mutation of the $\mathrm{p} 53$ suppressor gene has been reported in

*To whom correspondence should be addressed. hepatoma caused by aflatoxin ${ }^{2-5)}$, in angiosarcoma caused by vinyl chloride ${ }^{6}$, and in lung cancer caused by $\operatorname{radon}^{7,8)}$.

Malignant mesothelioma is caused by exposure to asbestos, an occupational and environmental carcinogen ${ }^{9)}$ that can damage DNA through the production of reactive oxygen ${ }^{10)}$. Alterations in the $\mathrm{p} 16^{11)}$ and $\mathrm{NF} 2^{12)}$ suppressor genes have been observed in 24 of $40(60 \%)$ and eight of 15 malignant mesothelioma cases (53\%), respectively; a history of asbestos 
exposure was proven in $60 \%$ of the cases in the former study ${ }^{11}$, but such information was not obtained in the latter study ${ }^{12}$. Single-point muation of the p53 suppressor gene has also been reported in two of 20 malignant mesothelioma cell lines (codons 245 and 278) ${ }^{13)}$, and two of the four cell lines (codons 175 and 245) ${ }^{14)}$.

However, the mutation observed in the cell lines requires careful interpretation, as point mutation of genes can occur during serial passage in vitro ${ }^{15}$. Therefore, analysis of the genes of primary tumors is necessary. Recently, eleven primary tumors of malignant mesothelioma, including those from cases with exposure to asbestos, were examined for the Ha-ras oncogene, but no mutation was found ${ }^{16}$. Similarly, no alteration in the p53 suppressor gene was demonstrated in 13 primary tumors of malignant mesothelioma, in which only two cases had a history of asbestos exposure ${ }^{17}$. Furthermore, no mutation has been observed for the Ki-ras oncogene in malignant mesothelioma cell lines ${ }^{13)}$.

In the present study, we analyzed the Ha- and Ki-ras oncogenes and the p53 suppressor gene in the primary tumor of seven malignant mesothelioma patients with a definite history of exposure to asbestos. The genetic analysis was made by the polymerase chain reaction-single strand comformation polymorphysm (PCR-SSCP) method in all patients. In additon, sequencing of deoxyribonucleic acid (DNA) was carried out in one of the patients.

\section{Subjects and Method}

The sex, age, occupation, exposure to asbestos, cell types of the malignant mesothelioma, and Brinkman's index of all seven patients who died of malignant mesothelioma are shown in Table 1. Histological diagnosis of malignant mesothelioma was performed by one of the present authors (H.A.), a qualified pathologist. The type of asbestos fibers was identified by the same author using an energy-dispersive X-ray spectrometer (JED-2001, JEOL DATUM, Tokyo) attached to a scanning microscope (JSM-5300LV, JEOL DATUM, Tokyo).

DNA was extracted from the formalin-fixed and paraffinembedded tissues of all seven patients by the following standard method ${ }^{18)}$ : From a block of the tissue specimens, $5-\mu \mathrm{m}$ sections were dissected. An area precisely corresponding to that of the tumor lesion was cut out from the sections, deparaffinized, and then digested with Proteinase $\mathrm{K}$ (Boehringen Mannheim GmbH, Mannheim). DNA was purified by means of phenol-chloroform extraction and ethanol precipitation, and was amplified by 30 to 40 cycles of polymerase chain reaction (PCR) ${ }^{19)}$ through the use of Gene Amplification PCR System 9600 (Perkin-Elmer Cetus, Norwalk, California). In the PCR, codons 1 to 31 (exon 1) and 34 to 93 (exon 2) of the Ha-ras oncogene were amplified, as mutation frequently occurs at codons 12,13 , and $61^{20)}$. Codons 1 to 37 (exon 1) and 48 to 80 (exon 2) of the Ki-ras oncogene were also amplified. Similarly, codons 126 to 307 (exons 5 to 9) of the p53 suppressor gene were amplified. The primers of the PCR used in this study are shown in the Appendix. The PCR products were further amplified with [alpha- ${ }^{32} \mathrm{P}$ ] dCTP at 20 to 40 cycles of reactions in a Quick Thermo II (Nippon Genetics, Tokyo, Japan) for PCR-SSCP analysis, and were then subjected to electrophoresis at 35 watts using $5 \%$ polyacrylamide gel with $5 \%$ glycerol added ${ }^{21,22)}$. The electrophoresis time was two to three hours, depending on the length of the amplified nucleotide. The gel was dried and exposed to X-ray film at room temperature for three to $24 \mathrm{hr}$ through the use of an intensification screen.

DNA was also extracted from the leucocytes of a healthy male volunteer, 29 years of age, and used as the normal control. Similarly, a DNA sample that had a GGC to GTC transversion at codon 12 (exon 1) in the Ha-ras oncogene

Table 1. Seven patients with malignant mesothelioma examined

\begin{tabular}{rlclclcr}
\hline No. & Sex & Death age & Occupation & $\begin{array}{c}\text { Asbestos } \\
\text { exposure years }\end{array}$ & Fiber types & $\begin{array}{c}\text { Cell types of } \\
\text { malignant mesothelioma }\end{array}$ & $\begin{array}{c}\text { Brinkman's } \\
\text { index* }\end{array}$ \\
\hline 1 & Male & 61 & Plumber & 20 & Crocidolite & Biphasic & 820 \\
2 & Male & 75 & Carpenter & 18 & Crocidolite & Sarcomatous & 800 \\
3 & Male & 90 & Plumber & 41 & Crocidolite & Epithelial & 550 \\
4 & Male & 67 & Electrician & 35 & Crocidolite & Sarcomatous & 533 \\
5 & Male & 54 & Plumber & 33 & Chrysotile & Epithelial & 0 \\
6 & Male & 52 & Storekeeper & 24 & Chrysotile & Epithelial & 384 \\
7 & Female & 64 & Housewife** & 10 & Chrysotile & Biphasic & 0 \\
\hline
\end{tabular}

*Number of cigarettes per day multiplied by years of smoking. ${ }^{* *}$ Washed the clothes of her husband (asbestos worker) for 10 years. 
and was obtained from a cell line of bladder cancer was used as the positive control. These DNA samples were analyzed by the same method as the samples taken from asbestos patients.

Sequence analysis of the Ha- and $\mathrm{Ki}$-ras oncogenes and p53 suppressor gene for the codons described above was conducted in one patient (Patient 1, Table 1), in order to confirm the normal pattern that was revealed through SSCP analysis. Sequencing reactions were carried out using a Dye Deoxy Terminator Cycle Sequencing kit, and the products were analyzed using the 373A Sequencer (Applied Biosystems Inc., Foster City, California).

\section{Results}

\section{PCR-SSCP analysis}

Neither mutation nor deletion in exons 1 and 2 of Haand $\mathrm{Ki}$-ras oncogenes, or in exons 5 to 9 of the p53 suppressor gene, were found in any of the seven malignant mesothelioma patients. Figure 1 illustrates the results for seven patients,

a) Ha-ras oncogene

Exon 1 ( codon 1 to 31 )

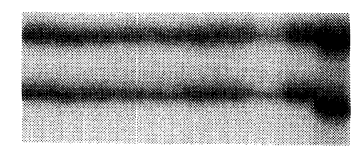

b) Ki-ras oncogene

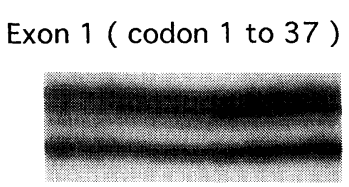

c) p53 suppressor gene

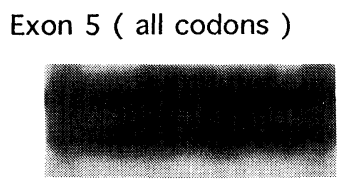

Exon 8 ( all codons )
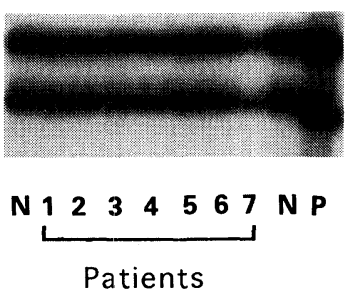

Exon 2 ( codon 34 to 93 )

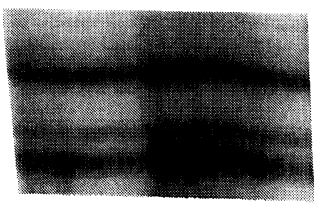

Exon 2 ( codon 48 to 80 )

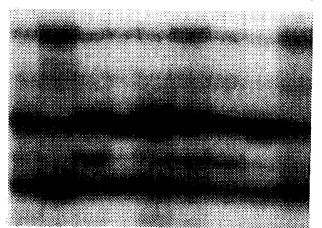

Exon 6 ( all codons )

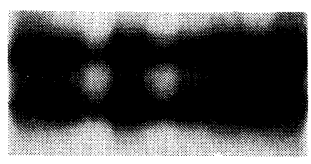

Exon 9 ( all codons )
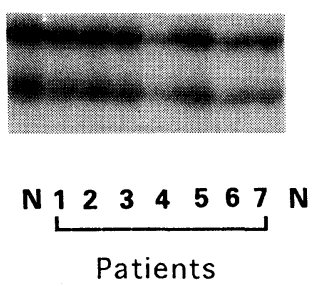

Exon 7 ( all codons )
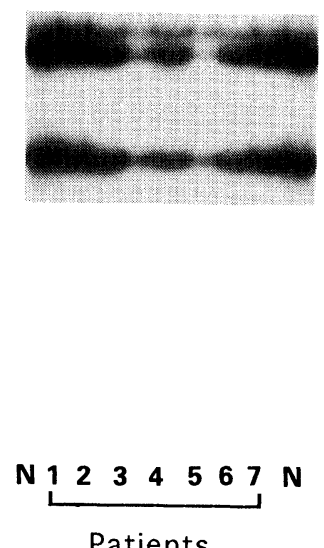

Fig. 1. Polymerase chain reaction-single strand comformation polymorphysm (PCR-SSCP) analysis of the Ha- and Ki-ras oncogene and p53 suppressor gene in the Normal control (N), seven patients (17), and Positive control (P) (one sample was loaded on two lanes for $N$ )

No mobility shift from $\mathbf{N}$ was found in any of the patients, whereas the shift is present in lane $\mathrm{P}$. 
the normal control, and the positive control. No mobility shift from the normal control was found in any patient, whereas the positive control did show a mobility shift.

\section{Sequencing analysis}

Sequencing analysis of the Ha- and Ki-ras oncogenes and of the p53 suppressor gene in Patient 1 failed to identify any alteration. We confirmed that these genes were of the wild-type pattern.

\section{Discussion}

This appears to be the first report in which a primary tumor was directly analyzed to examine changes in the ras oncogenes and p53 supressor gene simultaneously in malignant mesothelioma patients with a definite history of asbestos exposure. However, the study failed to demonstrate any genetic alteration in the $\mathrm{Ha}$ - and $\mathrm{Ki}$-ras oncogenes or the p53 suppressor gene. Further studies with a larger number of patients are required to reach a definite conclusion concerning the genetic effects of asbestos on malignant mesothelioma.

Neither was any mutation of the p53 suppressor gene was found in four heavy smokers with Brinkman's Indexes above 500 in the present study. This is not consistent with the report by Suzuki et al. $^{23)}$, who showed that mutation of the p53 suppresssor gene in non-small cell lung cancer was closely associated with lifetime cigarette smoking. Further studies are necessary to examine the effects of smoking on the p53 suppressor gene mutation in other malignant tumors.

It has been reported that activation and/or inactivation of oncogenes and suppressor genes such as myc, abl, erb, RB1, WT1, and DCC are associated with tumorigenesis ${ }^{24}$. Furthermore, it has been reported that the odds ratio for development of malignant mesothelioma in men highly exposed to asbestos is increased in those who have both the glutathione S transferase M1 gene (GSTM1) null genotype and the $\mathrm{N}$-acethyltransferase 2 gene (NAT2) slow acetylator genotype, which code the detoxic enzyme, suggesting that the GSTM1 and NAT2 polymorphisms play an important role in the development of malignant mesothelioma due to asbestos exposure ${ }^{25)}$. Further studies of various genes, such as $\mathrm{p} 16, \mathrm{NF} 2$, and those genes ${ }^{11,12,24,25)}$ found in the primary tumors of malignant mesothelioma with definite exposure to asbestos, are necessary. In addition, as the detective sensitivity of the denaturing gradient gel electrophoresis (DGGE) is higher than that of SSCP analysis, use of the former method is preferable over that of the latter ${ }^{26}$.

\section{Acknowledgments}

We would like to thank Dr. Shunji Yamamori, Mr. Kaoru Omura, and all other staff members of the Department of Gene Analysis of the Mitubishi Kagaku Bio-ClinicalLaboratories, Inc., Tokyo. Thanks are also due to Mr. Susumu Sakurai of the Clinical Laboratory at Tokyo University Hospital and Dr. Keiji Kanamori of the Department of Public Health, Faculty of Medicine for their technical collaboration, and Dr. Kazuhito Yokoyama of the Department of Public Health, Faculty of Medicine for his valuable suggestions.

\section{References}

1) Harris CC (1991) Chemical and physical carcinogenesis: Advances and perspectives for the 1990s. Cancer Res 51, 5023s-44s.

2) Aguilar F, Harris CC, Sun T, Hollstein M, Cerutti $P$ (1994) Geographic variation of p53 mutational profile in nonmalignant human liver. Science 264, 1317-9.

3) Hollstein MC, Wild CP, Bleicher F, Chutimataewin S, Harris CC, Srivatanakul P, Montesano R (1993) p53 mutations and aflatoxin $B_{1}$ exposure in hepatocellular carcinoma patients from Thailand. Int J Cancer 53, 515.

4) Aguilar F, Hussain SP, Cerutti P (1993) Aflatoxin $B_{1}$ induces the transversion of $G$ to $T$ in codon $249 \mathrm{p} 53$ tumor suppressor gene in human hepatocytes, Proc Natl Acad Sci USA 90, 8586-90.

5) Ozturk M, Collaborators (1991) p53 mutation in hepatocellular carcinoma after aflatoxin exposure. Lancet 338, 1356-9.

6) Hollstein M, Marison M-J, Lehman T, Welsh J, Harris CC, Martel-Planche G, Kusters I, Hontesano R (1994) p53 mutations at A:T base pairs in angiosarcomas of vinyl chloride-exposed factory workers. Carcinogenesis 15, 1-3.

7) Taylar JA, Watson MA, Devereux TR, Michels RY, Saccomanno G, Anderson M (1994) p53 mutation hotspot in radon-associated lung cancer. Lancet 343, 86-7.

8) Vahakangas KH, Samet JM, Metcalf RA, Welsh JA, Bennett WP, Lane DP, Harris CC (1992) Mutations of p53 and ras genes in radon-associated lung cancer from uranium miners. Lancet 339, 576-80.

9) Wagner JC, Sleggs CA, Marchand P (1960) Diffuse pleural mesothelioma and asbestos exposure in the north western cape province. Brit J Industr Med 17, 260-71. 
10) Broaddus VC, Yang L, Scavo LM, Ernst JD, Boylan AM (1996) Asbestos induces apoptosis of human and rabbit pleural mesothelioma cells via reactive oxygen species. J Clin Invest 98, 2050-9.

11) Cheng JQ, Jhanwar SC, Klein WM, Bell DW, Lee WC, Altomare DA, Nobori T, Olopade OI, Buckler AJ, Testa JR (1994) p16 alterations and deletion mapping of 9p21-p22 in malignant mesothelioma, Cancer Res 54, 5547-51.

12) Bianchi AB, Mitsunaga SI, Cheng JQ, Klein WM, Jhanwar SC, Seizinger B, Kley N, Klein-Szanto AJP, Testa JR (1995) High frequency of inactivating mutations in the neurofibromatosis type 2 gene (NF2) in primary malignant mesothelioma, Proc Natl Acad Sci 92, 10854-8.

13) Metcalf RA, Welsh JA, Bennett WP, seddon MB, Lehman TA, Pelin K, Linnainmaa K, Tammilehto L, Mattson K, Gerwin BI, et al. (1992) p53 and Kirstenras mutations in human mesothelioma cell lines, Cancer Res 52, 2610-5.

14) Cote RJ, Jhanwar SC, Novick S, Pellicer A (1991) Genetic alterations of the $\mathrm{p} 53$ gene are a feature of malignant mesotheliomas. Cancer Res 51, 5410-6.

15) Janssen WJ, Lyon J, Steenvorden ACM, Seliger H, Artram CR (1987) Concurrent mutations in two different ras genes in acute myeloid leukemias, Nucleic Acids Res 15, 5669-80.

16) Cristaudo A, Vivaldi A, Sensales G, Guglielmi G, Ciancia E, Elisei R, Ottenga F (1995) Molecular biology studies on mesothelioma tumor samples: Preliminary data on H-ras, P21, and SV40. J Environ Ptho Toxico and Oncology 14, 29-34.

17) Mor $O$, Yaron $P$, Huszar M, Yellin A, Jakobovitz $O$, Brok-Simoni F, Rechavi G, Reichert N (1997) Absence of p53 mutations in malignant mesothelioma. Am J Respir Cell Mol Biol 16, 9-13.

18) Goelz SE, Hamilton SR, Vogelstein B (1985) Purification of DNA formaldehyde fixed and paraffin embedded human tissue. Biochemical and biophysical communications 130, 118-26.

19) Saiki PD, Gelfand DH, Stoffel S, Scharf SJ, Higuchi R, Horn GT, Mullis KB, Erich HA (1988) Primerdirected enzymatic amplification of DNA with a thermostable DNA polymerase, Science 239, 487-91.

20) Bos JL (1989) ras oncogenes in human cancer: A review. Cancer Res 49, 4682-9.

21) Hayashi K (1991) PCR-SSCP: A simple and sensitive method for detection of mutations in the genomic DNA,
PCR methods and aplicatuons. 1, 34-8.

22) Hayashi K, Yandell DW (1993) How sensitive is PCRSSCP? Human Mutation 2, 338-46.

23) Suzuki H, Takahashi T, Kuroishi T, Suyama M, Ariyoshi Y, Takahashi T, Ueda R (1992) p53 mutations in nonsmall cell lung cancer in Japan: association between mutations and smoking, Cancer Res 52, 734-6.

24) Reddy EP, Skalka AM, Curran T (1998) The oncogene handbook. Elsevier science publishing company, Inc, New York.

25) Hirvonen A, Pelin K, Tammilehto L, Karjalainen A, Mattson K, Linnainmaa K (1995) Inherited GSTM1 and NAT2 defects as concurrent risk modifiers in asbestos-related human malignant mesothelioma. Cancer Res 55, 2981-3.

26) Beck JS, Kwitek AE, Cogen PH, Metzger AK, Duyk GM, Sheffield VC (1993) A denaturing gradient gel electrophoresis assay for sensitive detection of p53 mutations. Hum Genet 91, 25-30.

\section{Appendix}

Sequence of the primers of $\mathrm{PCR}$ used in this study ( $\mathrm{S}=$ sense primer, $A=$ antisense primer, respectively).

Ha-ras

codon 12, 13 S:5'-TGAGGAGCGATGACGGAATA-3' A:5'-TTCGTCCACAAAATGGTTCT-3'

codon 61 S:5'-AGGTGGTCATTGATGGGGAG-3' A:5'-TGGATGTCCTCAAAAGACTT-3'

Ki-ras

codon 12, 13 S:5'-GGCCTGCTGAAAATGACTGA-3' A:5'-GTCCTGCACCAGTAATATGC-3' codon 61 S:5'-GGAGAAACCTGTCTCTTGG-3' A:5'-CACAAAGAAAGCCCTCCCCA-3'

p53

exon 5 S:5'-TTCAACTCTGTCTCCTTCCT-3' A:5'-CAGCCCTGTCGTCTCTCCAG-3' exon 6 S:5'-GCCTCTGATTCCTCACTGAT-3' A:5'-TTAACCCCTCCTCCCAGAGA-3' exon 7 S:5'-AGGCGCACTGGCCTCATCTT-3' A:5'-AGGGGTCAGCGGCAAGCAGA-3'

exon 8 S:5'-AGCTTAGGCTCCAGAAAGGA-3' A:5'-TTTCTTCTTTGGCTGGGGAG-3'

exon 9 S:5'-CACTAAGCGAGGTAAGCAAG-3' A:5'-CGGCATTTTGAGTGTTAGAC-3' 